\title{
Trauma Scores, Accident Deformity Codes, and Car Restraints in Children
}

\author{
By R.A. Drongowski, A.G. Coran, R.F. Maio, and T.Z. Polley, Jr \\ Ann Arbor, Michigan
}

\begin{abstract}
- The importance and effectiveness of the appropriate use of automobile restraints by young children has been emphasized in several studies. Once the child has entered the emergency care system, however, restraint use may not be the best predictor of injury severity. This study was undertaken to investigate the relationship of restraint status to morbidity and mortality in children examined in a hospital emergency facility following involvment in a motor vehicle crash (MVC). The emergency room charts of 101 children under 18 years of age, who were victims of MVCs, were reviewed and the following trauma scores were calculated: Glascow Coma Scale, Pediatric Trauma Score, Revised Trauma Score, Injury Severity Score, and Maximum Abbreviated Injury Score. In addition, the Traffic Accident Damage (TAD) score, an estimate of crash severity determined by the police at the accident scene, was recorded. The patients were age stratified as follows: 0 to 4 years $(n=24), 5$ to 11 years $(n=29$ ), and 12 to 17 years $(n=48$ ). Fifty patients were appropriately restrained at the time of the crash. There was a significant correlation between mean trauma scores and mean TAD codes $(P<.05)$. There were no significant differences in mean trauma scores between improperly restrained $(n=11)$ and unrestrained $(n=40)$ children $(P>.05)$ across all age groups, and these children were grouped together as "unrestrained" in further analyses. In the 0 to 4 age group, there were no significant differences in mean trauma scores between restrained and improperly restrained or unrestrained children in contrast to the 5 to 11 and the 12 to 17 age groups. There were no significant difference between the distribution of restrained and unrestrained victims with regard to mean TAD scores $(P=.5224)$ in the 0 to 4 age group. This study demonstrates a close correlation between mean trauma scores and vehicle deformity in all age groups, and shows that mean trauma scores appear to be independent of restraint use for the 0 to 4-year-old age subset. Therefore, a police-assigned crash severity score, such as the TAD, may be useful in the initial triage of pediatric trauma victims to an appropriate hospital or trauma center. Copyright $\odot 1993$ by W.B. Saunders Company
\end{abstract}

INDEX WORDS: Motor vehicle accident trauma; injury severity scores.

OTOR VEHICLE trauma has been identified as one of the leading causcs of morbidity and mortality in young children. ${ }^{1-3}$ Consequently, many

From the Section of Pediatric Surgery, C.S. Mott Children's Hospital and University of Michigan Medical School, Ann Arbor, MI.

Presented at the 39th Annual International Congress of the British Association of Paediatric Surgeons, Leeds, England, July 15-18, 1992.

Address reprint requests to Amold G. Coran, MD, Section of Pediatric Surgery, L2110 Maternal-Child Health Center, University of Michigan Medical Center, Ann Arbor, MI 48109-0245.

Copyright $\mathbb{1} 1993$ by W.B. Saunders Company

0022-3468/93/2808-0027\$03.00/0 states have passed laws regarding mandatory automobile restraint usage by children in an effort to reduce the injuries associated with motor vehicle crashes (MVCs), and subsequent studies have documented the beneficial effects of these mandates. ${ }^{4-11}$ In conjunction with these efforts, there has been a considerable amount of research spent on developing effective automobile child restraints. ${ }^{12,13}$ In spite of the development of special pediatric restraints, no restraint system can be $100 \%$ effective in preventing morbidity and mortality in every type of crash; and, in some instances, the restraint itself, particularly a lap belt, can be a source of significant injury to the child. ${ }^{14-18}$ Misuse of child restraints can also lead to injury. ${ }^{19,20}$ Therefore, it should not be assumed that rcstraincd children will not be injured, particularly in the more severe crashes. In addition, some studies of restrained children, especially of children less than 4 years of age, have demonstrated significant injury following MVCs, which raises questions concerning the efficacy of these restraints in this age group. ${ }^{18,21}$ However, a lower risk of injury to restrained children should be expected within the entire population of MVC victims, and the same should be expected among those entering the emergency medical care system.

This study investigates the likelihood of injury among restrained and unrestrained children, examined in a hospital emergency facility, by analyzing the relationship between trauma scores, Traffic Accident Deformity codes, and the use of appropriate restraints in three different age groups: 0 to 4,5 to 11 , and 12 to 17 years of age. We hypothesized that the use of appropriate automobile restraints in children would result in significantly lower trauma scores than in children who were either improperly restrained or unrestrained.

\section{MATERIALS AND METHODS}

The study cohort consisted of 101 children less than 18 years of age who were evaluated in the emergency department of a university hospital with level I trauma center capabilities between June 1990 and March 1991 for trauma associated with MVCs. The patients' emergency room charts were reviewed and from these the following trauma severity scores were calculated: Glascow Coma Scale (GCS), ${ }^{22}$ Pediatric Trauma Score (PTS), ${ }^{23}$ Revised Trauma Score (RTS), ${ }^{, 4}$ Maximum Abreviated Injury Score (MAIS), ${ }^{25,26}$ Injury Severity Score (ISS), ${ }^{27}$ and predicted mortality using the Trauma Scores and Injury Severity Score (TRISS) ${ }^{28}$ methodology. 
The patients were stratified according to the following age categories: 0 to 4 years $(n=24), 5$ to $11(n=29)$, and 12 to $17(n=48)$.

Parent/patient interviews were carried out and Traffic Accident Damage (TAD) codes were obtained from copies of the State of Michigan Official Traffic Accident Report for each accident. The TAD rating system in Michigan consists of a 7-point scale, with higher scores indicative of more severe vehicle deformation. TAD scores (as coded by the police at the accident scene on the State of Michigan Official Traffic Accident Report) were grouped into three categories as follows: a low severity crash was coded 0,1 , or 2; a moderately severe crash was coded 3,4 , or 5 ; and severe crash was coded 6 or 7 . The following information was obtained from these reports: use of restraint by victim, type of restraint employed, patient position in the vehicle, and TAD code.

Specific injuries sustained by each child were coded using the Abbreviated Injury Scale (AIS-85). The AIS is an anatomically based system that classifies individual injuries by body region on a 6-point ordinal severity scale ranging from AIS $=1$ (minor) to AIS $=6$ (Untreatahle) ${ }^{29}$ The MAIS is the single highest Abbreviated Injury Scale (AIS-85) code for children with multiple injuries; for children with only one injury the AIS is the same as the MAIS. The ISS, a summary of the severity score for anatomic injuries, was calculated using the personal computer injury coding software program 'Tri-Code'. 30

Properly restrained patients were defined as those children using government-approved safety restraints according to both position in car and age (ie, front seat passengers with both lapbelts and shoulder harnesses secured, lapbelts for children in rear seats, and infants in restraint devices secured in proper position as directed by the manufacturer). Improperly restrained children included the following situations: two persons secured by the same seatbelt, the shoulder harness placed behind the child and not securing an infant seat with the car's lapbelt or not placing the infant in the correct position in the restraint, ie, front facing for a rear-facing device.

Emergency room costs included hospital and physician fees, while inpatient costs did not include physician fees.

Statistical analysis was performed on the Michigan Interactive Data Analysis System (MIDAS) using Student's $t$ test, $\chi^{2}$ analysis, and analysis of variance with $P$ values $<0.05$ considered significant

\section{RESULTS}

The 101 patients were stratified into the following three age groups: 0 to 4 years $(n=24), 5$ to 11 years $(n=29)$, and 12 to 17 years $(n=48)$. There were 45 boys and 56 girls. Eighteen of the patients were involved in an accident in which alcohol was a factor. Fifty-three patients were discharged home following evaluation in the emergency room, while 48 patients were subsequently admitted to the hospital. Six children died. Fifty patients were identified as being properly restrained, 40 children used no restraint, while the remaining 11 were improperly restrained (Table 1).

Mean trauma severity scores, hospital costs, and length of hospital stay were correlated with TAD codes (Table 2). Higher TAD codes correlated with more severe mean trauma severity scores, a longer mean length of hospital stay, an increased emergency room cost, and increased inpatient hospital costs.

There were no significant differences in mean

\begin{tabular}{lc}
\multicolumn{2}{c}{ Table 1. Demographic Data } \\
$\begin{array}{c}\text { Variable } \\
\text { Sex }\end{array}$ \\
Male & 45 \\
Female & 56 \\
Age (yr) & \\
0 to 4 & 24 \\
5 to 11 & 29 \\
12 to 17 & 48 \\
Alcohol-related accident & \\
Yes & 18 \\
No & 83 \\
Disposition & \\
Home & 53 \\
Inpatient & 48 \\
Outcome & \\
Lived & 95 \\
Died & 6 \\
Restraint & \\
Proper & 50 \\
Improper & 11 \\
None & 40 \\
\hline
\end{tabular}

trauma severity scores between those children improperly restrained $(n=11)$ and those not restrained $(n=40)$ at the time of the accident across all age groups (Table 3), and these children were grouped together as "unrestrained" in further analysis.

Contrary to our hypothesis, there were no significant differences in mean trauma severity scores within the 0 to 4-year age range between restrained and unrestrained children $(P>.05)$. In contrast, there were significant differences in the mean trauma severity scores between restrained and unrestrained children in both the 5 to 11 and 12 to 17 year age groupings $(P<.05)$ (Table 4$)$.

There were no significant differences in the TAD codes between the restrained and unrestrained children in the 0 to 4 year age group $(P=.5224)$ (Table 5).

\section{DISCUSSION}

Numerous studies ${ }^{31-33}$ have evaluated various trauma scoring systems in the pediatric population

Table 2. Trauma Score Correlation With Traffic Accident Damage Code $(\mathbf{n}=101)$

\begin{tabular}{lccc}
\hline & \multicolumn{3}{c}{ Traffic Accident Damage Code } \\
\cline { 2 - 4 } \multicolumn{1}{c}{ Trauma Scores } & Low & Moderate & Severe \\
\hline GCS & 15.0 & 14.4 & 11.6 \\
PTS & 11.6 & 10.7 & 7.9 \\
RTS & 7.8 & 7.5 & 6.7 \\
TRISS & 99.8 & 97.1 & 92.2 \\
ISS (MTOS) & 0.8 & 3.6 & 9.4 \\
MAIS & 1.07 & 1.53 & 2.75 \\
Length of Stay (d) & 3.0 & 3.4 & 18.2 \\
Emergency room costs (US\$) & 229.00 & 368.00 & 980.00 \\
Inpatient costs (US\$) & $2,769.00$ & $10,320.00$ & $24,914.00$ \\
\hline
\end{tabular}


Table 3. Trauma Scores in Improperly Restrained and Unrestrained Children $(\mathbf{n}=\mathbf{5 1})$

\begin{tabular}{lccc}
\hline Trauma Scores & $\begin{array}{c}\text { Improperty } \\
\text { Restrained } \\
(\mathrm{n}=11)\end{array}$ & $\begin{array}{c}\text { Unrestrained } \\
(\mathrm{n}=40)\end{array}$ & PValue \\
\hline GCS & 11.5 & 12.6 & .4979 \\
PTS & 8.4 & 8.9 & .6901 \\
RTS & 6.6 & 7.0 & .4706 \\
TRISS & 91.9 & 93.8 & .7725 \\
ISS (MTOS) & 9.9 & 7.7 & .3958 \\
MAIS & 2.54 & 2.38 & .7040 \\
\hline
\end{tabular}

for use in assessing injury severity, determining the most sensitive and specific indicator of trauma in children and for use as a field triage tool. The Major Trauma Outcome Study helped establish the RTS as an effective physiological indicator of injury severity and the ISS as an effective anatomical indicator of injury severity. ${ }^{34}$ Recently, the PTS has been evaluated as an effective tool in assessing trauma severity in children. ${ }^{23}$

There has been extensive development and assessment of infant and child restraint devices over the past two decades. Development of effective passive restraint systems, shoulder belts, harnesses, and air bags are testimony to the effort put forth by automobile manufacturers in this regard. However, trauma continues to be one of the leading causes of morbidity and mortality in children, with motor vehicle trauma the highest single cause of injury in children.

This study has demonstrated the relationship which exists between trauma severity scores, TAD codes, and the use of vehicle restraints in children. There exists a significant relationship between TAD codes and trauma severity scores, with more severe trauma associated with a higher TAD rating. Also, the length of hospital stay, emergency room costs, and inpatient hospital costs are directly correlated with the TAD codes. This gives credence to the fact that the TAD codes assigned by police officers are excellent predictors of injury severity in children involved in these accidents.
Table 5. Traffic Accident Damage Code and Seatbeit Use

\begin{tabular}{cccccc}
\hline & & \multicolumn{4}{c}{$\begin{array}{c}\text { Traffic Accident } \\
\text { Damage Code }\end{array}$} \\
\cline { 3 - 6 } Age & $\begin{array}{c}\text { Seat Belt } \\
\text { Use }\end{array}$ & Low & Moderate & Severe & $x^{2}$ Value \\
\hline $0-4$ yr $(n=24)$ & Yes & 3 & 7 & 4 & .5224 \\
& No & 1 & 4 & 5 & \\
$5-11$ yr $(n=27)$ & Yes & 3 & 9 & 1 & .0010 \\
$12-17$ yr $(n=48)$ & No & 0 & 6 & 8 & \\
& Yes & 5 & 11 & 6 & .0495 \\
& No & 2 & 8 & 16 & \\
\hline
\end{tabular}

Improper use of restraints (eg, two persons with one belt, not securing an infant seat properly, placing front seat in reclining position with shoulder belt behind a child's back) yielded mean trauma severity scores not significantly different from those experienced by children unrestrained. This suggests that the development of foolproof, passive restraint systems for children, as well as adults, is a goal not yet realized by automobile safety engineers.

The most interesting finding of this study is that, in the 0 to 4-year age group $(n=24)$, trauma severity scores were not significantly different between restrained and unrestrained children. In contrast, there were significant differences in trauma severity scores in both the 5 to 11 and 12 to 17 age groups between unrestrained and restrained passengers. Trauma scores were first developed for assessment of injuries in the adult population and were subsequently applied to children. There have been numerous studies which indicate that the RTS, PTS, and MAIS are excellent indicators of injury severity in children. Therefore, the absence of this difference in the 0 to 4 age group is not due to the insensitivity of the trauma severity scores in children.

In conclusion, this study demonstrates a close correlation between mean trauma scores and vehicle deformity in all age groups, and shows that mean trauma scores appear to be independent of restraint useage for the 0 to 4-year old age subset. Therefore, a police-assigned crash severity score, such as the $\mathrm{TAD}$, may be useful in the initial triage of pediatric trauma victims to an appropriate hospital or trauma center.

Table 4. Trauma Scores in Restrained and Unrestrained Children by Age

\begin{tabular}{|c|c|c|c|c|c|c|c|c|c|}
\hline \multirow{3}{*}{$\begin{array}{l}\text { Trauma } \\
\text { Scores }\end{array}$} & \multicolumn{9}{|c|}{ Age Range } \\
\hline & \multicolumn{3}{|c|}{0 to 4 years $(n=24)$} & \multicolumn{3}{|c|}{5 to 11 years $(n=29)$} & \multicolumn{3}{|c|}{12 to 17 years $(n=48)$} \\
\hline & $\mathrm{A}\{14\}$ & UR (10) & PValue & $R(14)$ & $\operatorname{UR}(15)$ & $\rho$ Value & $\mathrm{R}(22)$ & UR (26) & $P$ Value \\
\hline GCS & 14.1 & 13.1 & .5189 & 15.0 & 11.6 & .0128 & 14.5 & 12.5 & .0542 \\
\hline PTS & 9.4 & 8.8 & .6818 & 11.4 & 8.3 & .0052 & 11.3 & 9.0 & .0050 \\
\hline RTS & 7.2 & 7.2 & .9874 & 7.7 & 6.6 & .0449 & 7.7 & 7.0 & .0882 \\
\hline TRISS & 93.4 & 95.1 & .8367 & 99.7 & 92.5 & .1703 & 99.6 & 93.2 & .1459 \\
\hline ISS (MTOS) & 3.3 & 6.0 & .3445 & 2.3 & 8.4 & .0031 & 2.6 & 8.8 & .0011 \\
\hline MAIS & 1.36 & 1.9 & .2745 & 1.29 & 2.67 & .0016 & 1.46 & 2.42 & .0067 \\
\hline
\end{tabular}

Abbreviations: $R$, restrained; UR, unrestrained. 


\section{REFERENCES}

1. Greensher J: Prevention of childhood injuries. Pediatrics 74:970-975, 1984 (suppl)

2. Alcoff JM: Car seats for children. Am Fam Physician 25:167171,1982

3. Agran P, Castillo D, Winn D: Childhood motor vehicle occupant injuries. Am J Dis Child 144:653-662, 1990

4. Latimer EA, Lave LB: Initial effects of the New York State auto safety belt law. Am J Public IIealth 77:183-186, 1987

5. Agran PF, Dunkle DE, Winn DG: Effects of legislation on motor vehicle injuries to children. Am J Dis Child 141:959-964, 1987

6. Wagenaar AC, Webster DW, Maybee RG: Effects of child restraint laws on traffic fatalaties in eleven states. J Trauma 27:726-732, 1987

7. Williams AF, Wells JK: The Tennessee child restraint law in its third year. Am J Public Health 71:163-165, 1981

8. Paulson JA: The case for mandatory seat restraint laws. Clin Pediatr 20:285-290, 1981

9. Stulginskas JV: Effects of a seat belt law on child restraint use. Am J Dis Child 137:582-585, 1983

10. Wagenaar AC, Webster DW: Preventing injuries to children through compulsory automobile safety seat use. Pediatrics 78:662672,1986

11. Kahane CJ: An Evaluation of Child Passenger Safety-The Effectiveness and Benefits of Safety Seats. Washington, DC, National Highway Traffic Safety Administration, DOT HS 806890,1986

12. Decker MD, Dewey MJ, Hutcheson RH, et al: The use and efficacy of child restraint devices. JAMA 252:2571-2575, 1984

13. Hitchcock RJ, Nash CE: Protection of children and adults in crashes of cars with automatic restraints. Proceedings of the 8 th International Technical Conference On Experimental Safety Vehicles. Washington, DC, National Highway Traffic Safety Administration, 1981, pp 317-325

14. Marcus DF: Child car seats: A must for safety. Pediatr Nurs 7:13-17.65, 1981

15. Arajarvi E. Santavirta S: Chest injuries in severe traffic accidents by seatbelt wearers. J Trauma 29:37-41, 1989

16. Sato TB: Effects of seat belts and injuries resulting from improper use. J Trauma 27:754-758, 1987

17. Agran PF, Wirm D: Traumatic injuries among children using lap belts and lap/shoulder belts in motor vehicle collisions. Proceedings of the 31st Annual American Association For Automotive Medicine, New Orleans, LA, 1987

18. Agran PF, Dunkle DE, Winn DG: Motor vehicle accident trauma and restraint usage patterns in children less than 4 years of age. Pediatrics 76:382-386, 1985

19. Hoffman MA, Spence LJ, Wesson DE, et al: The pediatric passenger: Trends in seatbelt use and injury patterns. J Trauma 27:974-976, 1987
20. Morris JB: Protection for 5-12 year old children. Proceedings of the SAE Child Injury And Restraint Conference. Washington, DC, National Highway Traffic Safety Administration, Office of Vehicle Research, 1983, pp 89-100

21. Agran PF, Dunkle DE. Winn DG: Restraint usage patterns of children less than four years of age evaluated in a medical setting after a motor vehicle accident. Proceedings of the 28th Annual American Association For Automotive Medicine, Denver, CO, 1984

22. Teasdale G, Jennett B: Assessment of coma and impaired consciousness. Lancet 2:81-84, 1974

23. Tepas JJ, Mollitt DL, Talbert $\mathbf{J L}$, et al: The Pediatric Trauma Score as a predictor of injury severity in the injured child. $\mathrm{J}$ Pediatr Surg 22:14-18, 1987

24. Champion HK, Sacco WJ, Copes WS, et al: A revision of the Trauma Score. J Trauma 29:623-629, 1989

25. Agran P, Winn D, Dunkle D: Injuries among 4- to 9-year-old restrained motor vehicle occupants by seat location and crash impact site. Am J Dis Child 143:1317-1321, 1989

26. Agran PF, Dunkle DE, Winn DG: Injuries to a sample of seatbelted children evaluated and treated in a hospital emergency room. J Trauma 27:58-64, 1987

27. Baker SP, O'Neill B, Haddon W, et al: The Injury Severity Score: A method for describing patients with multiple injuries and evaluating emergency care. J Trauma 14:187-196, 1974

28. Boyd CR, Tolson MA, Copes WS: Evaluating trauma care: The TRISS method. J Trauma 27:370-378, 1987

29. Committee On Injury Scaling; The Abbreviated Injury Scale. Des Plaines, IL, American Association For Automotive Medicine, 1990

30. Tri-Code. Personal Computer Injury Coding Software. TriAnalytics, Inc, Bel Air, MD; and The Association For The Advancement Of Automotive Medicine, Des Plains, IL, 1989

31. Eichelberger MR, Gotschall CS, Sacco WJ, et al: A comparison of the Trauma Score, the Revised Trauma Score, and the Pediatric Trauma Score. Ann Emerg Med 18:1053-1058. 1989

32. Wesson DE. Williams JI, Spence LJ, et al: Use of ISS in a pediatric population. Proceedings of the 30th Annual American Association For Automotive Medicine, Montreal, Quebec, 1986, pp 153-161

33. White BF, Read JH, Panlilio VP: An evaluation of the Injury Severity Score in a pediatric population: The light truck and van study. Proceedings of the Canadian Multidisciplinary Road Safety Conference V, Calgary, Alberta, 1987, pp 308-316

34. Champion HR, Copes WS, Sacco WJ, et al: The Major Trauma Outcome Study: Establishing national norms for trauma care. J Trauma 30:1356-1365, 1990 